\title{
Safe and Legal Fish Waste Composting in Alaska
}

\section{Introduction}

This Sea Gram is an effort to encourage local soils production using fish wastes and to teach the reader about the safety and legal aspects of composting fish waste, in compliance with Alaska statutes and the Alaska Administrative Code (AAC). It is not a how-to guide for beginning composters. For more information on composting, specifically in Alaska, see the References section. That said, there is very little difference between composting fish waste and composting vegetable scraps. The main distinction is that fish waste is very high in nitrogen, and thus it requires the addition of a greater amount of carbon, such as wood chips, cardboard, newspaper, or shredded paper.

Fish wastes, including entrails, backbones (sometimes referred to as "racks"), heads, and fins can be composted with minimal odor and without attracting animals and other pests, including flies. However, certain precautions must be taken to do it safely, effectively, and legally. The risk of causing a nuisance, attracting bears and other animals, and causing your entire neighborhood to reek of rotten fish guts is very real. One cannot enter into fish composting lightly or without first taking precautions. This publication can help minimize problems associated with fish waste composting in Alaska.

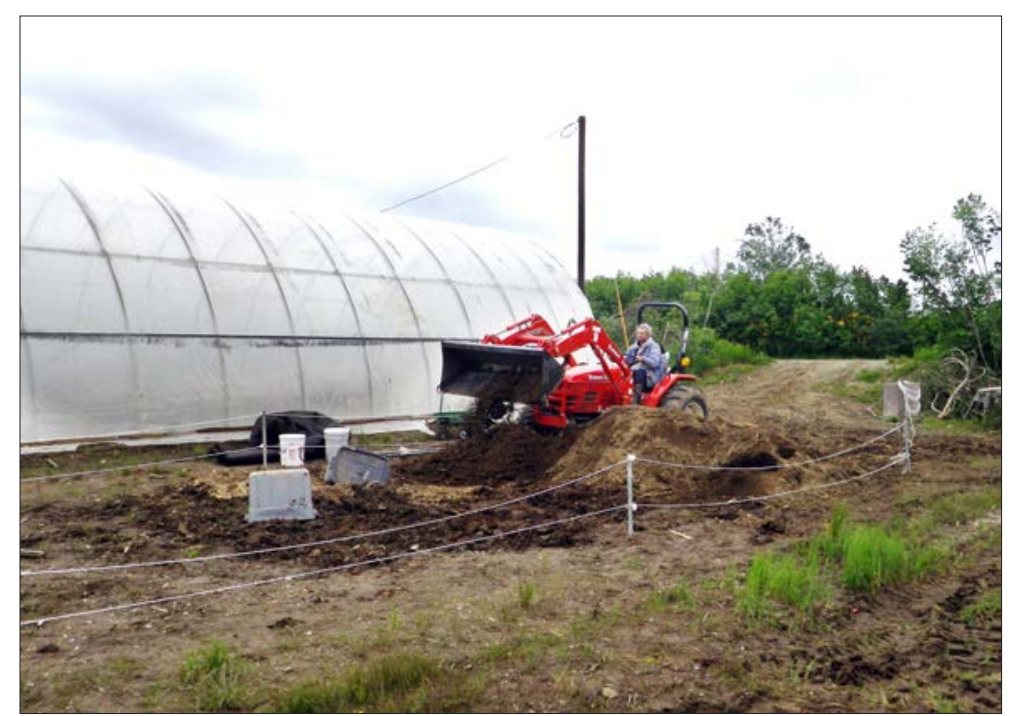

One benefit of composting in rural Alaska is producing a locally available soil amendment. An electric fence surrounds this compost area.

\section{Benefits of Composting}

Composting in Alaska, especially rural Alaska, holds numerous benefits. Chief among them is the end result of composting-a locally produced soil amendment. With the high costs of agricultural inputs and the rising freight costs to rural areas, composting is a viable and economical alternative to purchasing fertilizer, manure, and other inputs for your garden or farm. Whether you are a backyard gardener or a commercial agricultural producer (1) composting can greatly reduce your costs and improve your chances of success in gardening; (2) composting reduces garbage odors, as many noxious smells from a garbage can are the result of discarded compostable items; (3) composting will cut your waste disposal expense in municipalities that charge for the disposal of household wastes; and (4) composting is good for the environment because it reduces the amount of waste in landfills, reduces methane generation from landfills (one of the leading culprits of greenhouse gas emissions), and prevents fossilization of compostable food items. ${ }^{1}$

1 See William Rathje and Cullen Murphy, Rubbish!: The Archaeology of Garbage, University of Arizona Press, 2001. (Studies on what happens to waste after it has been disposed of in modern-day landfills.)

\section{by Izetta Chambers \\ Alaska Sea Grant Marine Advisory Program University of Alaska Fairbanks Bristol Bay Campus Dillingham, AK 99576 (907) 842-8323 izetta.chambers@alaska.edu}

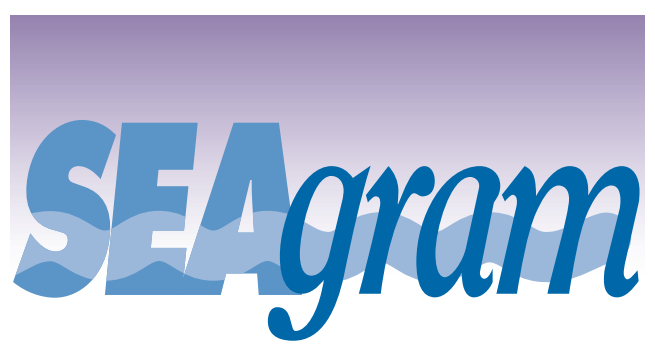

ALASKA SEA GRANT MARINE ADVISORY PROGRAM

ASG-55 2011

doi:10.4027/sIfwca.2011 
KEEP BACK!

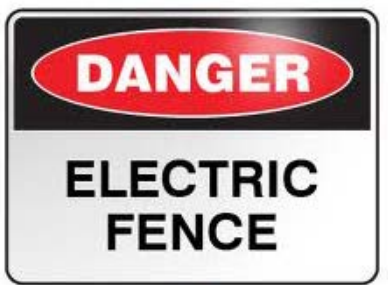

\section{Install and Mark an Electric Fence}

Before attempting any fish composting in Alaska, it is important to consider installing an electric fence around the perimeter of the area to be used for composting. If you live in bear country, or an area with a lot of wildlife that may be attracted to odors coming from decomposing food and fish waste, an electric fence will minimize interaction from curious, often destructive animals, especially bears. A note of caution: if you are using an electric fence, always clearly indicate that there is an electric fence installed. This will decrease the risk that children, or adults with heart problems or pacemakers, will stumble upon it and get hurt. Make sure to clearly mark the posts with graphic and written signs that show there is an electrical charge to the fence. You might also want to use words such as "Danger" or "Warning."

If you have a lot of small critters in your neighborhood, such as dogs and foxes that might be attracted to the site, I strongly recommend installing a second line of hot wire or hot rope to keep them out. The cost of these detractors is minimal compared to the cost of damage to your property, or fines from violating state law regarding attracting animals to your site.

\section{Legal Considerations}

According to Alaska statutes, land application of fish waste is allowed, with certain conditions. However, if a composter is not following the statutes, that person may be held liable for nuisance.

A person is guilty of creating or maintaining a nuisance if they place or

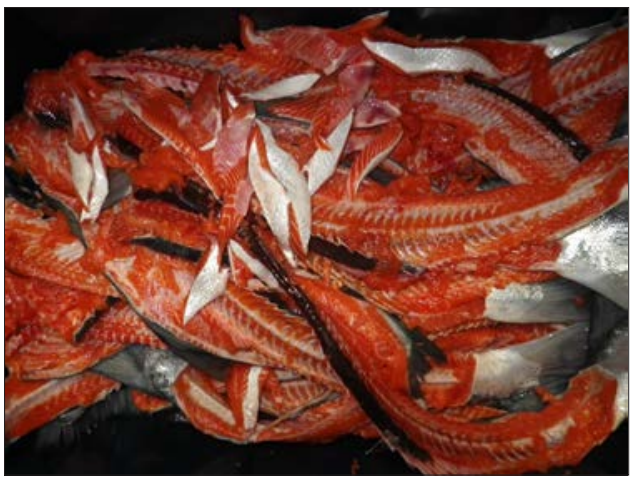
deposit "upon a lot, street, beach, or premises, or upon or anywhere within 200 feet of a public highway, any garbage, offal, dead animals, or any other matter or thing that would be obnoxious or cause the spread of disease or in any way endanger the health of the community." If a person neglects or refuses to stop the nuisance when told by order of an officer of the Department of Environmental Conservation, they may be found guilty of a misdemeanor and the court may be forced to assess damages against the person for the expense of stopping the nuisance.

Additionally, Alaska statute prohibits the "accumulation, storage, and treatment" of solid waste in a manner that attracts domestic animals, wildlife, or disease vectors. ${ }^{3}$ The administrative code requires that for legal

These fish racks have been scraped free of meat, and will break down faster in the composting phase. The backbone meat scrapings will be sold and used to make salmon burgers. application of fish processing waste to agricultural land for soil enhancement purposes, the waste must be:

- Ground to less than two inches in diameter;

- Treated to reduce the number of Salmonella spp. or fecal coliform bacteria to meet the Class A requirements for pathogen reduction at the time of land application (see 40 C.F.R. 503.15) (Note: in this Sea Gram, the "treatment" is the composting process itself, and achieving the appropriate temperature requirement for active composting);

- Incorporated into the soil surface when the waste is applied;

- Applied at or below the agronomic rate for nitrogen for any crop or vegetation that will be grown on the land;

- Applied in a manner that does not create an odor nuisance or attract animals or other vectors; and

- Applied in a manner that ensures that runoff of surface water from the disposal site does not violate the water quality standards in $18 \mathrm{AAC} 70$.

2 AS 46.03.810. Air and Land Nuisances.

318 AAC 60.010. Accumulation, Storage, and Treatment. 
The composting operation must not be located within 100 feet of a well that produces water suitable for drinking. ${ }^{4}$

\section{Composting Process}

Once the appropriate precautions are taken, the composting process should be undertaken with a lot of care. Also, it's a good idea to have appropriate controls in place to monitor the process. I advise against doing a one-time composting operation and hoping that it works. Composting is an active process. That means it changes over time, and must be continually monitored and controlled. Forming a compost heap with fish and walking away is a recipe for disaster. Please keep an eye on it, as the compost will change day by day and will require aeration (turning to incorporate oxygen into the pile).

The most important aspect of any type of composting is combining the correct balance of nitrogen, carbon, oxygen, and moisture. Heat is also important, but can be managed through maintenance of the right amounts of nitrogen, carbon, oxygen, and moisture. With fish composting, the nitrogen source is the fish. Carbon sources can include wood chips, newspaper, shredded office paper, cardboard, dead leaves, etc. The wood chips also perform the important function of aeration by making little pockets of air in the compost pile, resulting in less frequent turning of the pile. For fish composting with adequate carbon ratios, turning two times per week is preferable. More frequent turning may release noxious odors, and may release too much heat, inhibit bacterial decomposition,

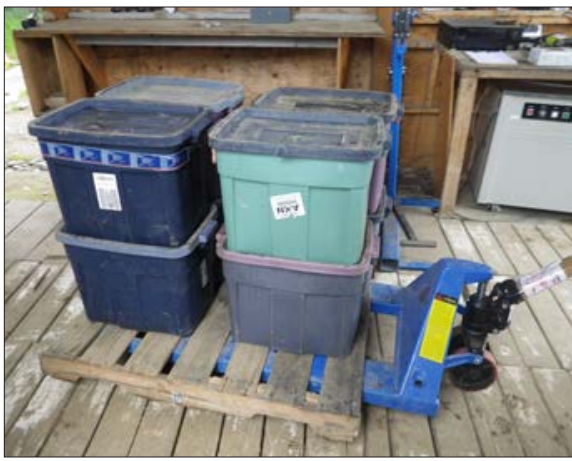

Make sure your fish waste is well-contained. Plastic totes with lids work well. and thus increase composting or curing times.

Because fish is such a rich source of nitrogen, some authorities recommend approximately seven parts carbon to one part fish (7:1 ratio). One consideration is how much carbon you have available. If you live in an area with few trees for chipping, and few other carbon sources, you may want to opt for starting with a lot less fish and making sure that you have plenty of carbon on hand for the composting process. That means that if you are composting one bucket of fish guts, weighing approximately 50 pounds, you will need 350 pounds of carbon. That is a lot of volume of wood chips, cardboard, and newspaper! Because you don't want to be playing "catch up," and chipping brush while your fish waste sits in a bucket turning anaerobic ${ }^{5}$, the best strategy is to have the carbon source ready to go as soon as you have the fish waste that you want to compost.

With any type of composting process, there is a strong emphasis on aerobic ${ }^{6}$ decomposition; anaerobic bacteria are not beneficial to the soil, produce noxious smells, and can actually decrease the availability of nitrogen to your plants, because the nitrogen will escape the pile as ammonia gas. Another sign of a poor fish compost is the "rotten egg" (hydrogen sulfide) smell. So, keeping the pile aerobic is very important.

If you have the correct ratio of carbon to nitrogen and the right level of moisture, your fish waste composting could be finished in as little as a few months. However, you will want to cure the compost for several months or more, possibly over winter, to ensure that the compost is fully decomposed. Additionally, unfinished and uncured fish waste compost will have a lot of persistent undecomposed material from fins, tails, and skin, which will invite fungal growth, including mushrooms, if applied to the garden. Mushroom growth is a sign that the soil has mycelium, which is the vegetative part of a fungus, a mass of branching, thread-like hyphae. Adding unfinished compost may increase your plants' susceptibility to mold and rot, so you may want to hold off on applying the compost for several months, or even until the next growing season.

4.18 AAC 60.040. Wellhead Protection.

5 Here anaerobic refers to decomposition in the absence of oxygen.

6 Aerobic decomposition takes place in the presence of oxygen. 
Izetta Chambers is a

Dillingham extension agent

with the Alaska Sea Grant

Marine Advisory Program,

University of Alaska

Fairbanks. She assists

fishermen and processors

with best business

management practices

and teaches residents how

to participate in NEPA

procedures. She holds a law

degree from the University

of Arizona James E. Rogers

College of Law.
Finished fish compost should have a pleasant, earthy smell to it, with only a slight hint of fish. If the compost is rank, slimy, or hot, it is not finished with the composting process, and should be incorporated back into the pile, preferably with a lot of carbon mixed in. A good rule of thumb is that compost you produce this summer will be available for use next spring, and can be incorporated directly into the top 3 inches of your garden beds.

\section{Conclusion}

Composting is not rocket science, but it can be problematic and dangerous if not undertaken in the correct manner. Fish composting is even trickier, as there are strict laws in Alaska regulating the processing of seafood wastes, and rules regarding accumulation, storage, and transport of fish wastes. However, if done correctly, the benefits of fish waste compost are great-improved soil, a free source of fertilizer for many years to come, and water quality improvement because less waste gets dumped into our rivers, estuaries, and bays.

\section{Acknowledgments}

I would like to especially thank Brian Himelbloom, Terry Johnson, and Paula Cullenberg for their editorial assistance. Also, a special thanks goes to Jodie Anderson, Jeff Smeenk, and Mingchu Zhang for their technical and scientific input on this topic. Their years of research on the science of fish composting proved invaluable during the drafting and review of this publication. Also, thanks to Gary Laursen, who provided insight on mushrooms and their interactions with decomposing fish in Alaska.

\section{References}

Anderson, Jodie. 2011. Composting in rural Alaska. BioCycle 52(7):22. http://www.jgpress. com/archives/ free/002390.html

Frederick, Lynn, Robin Harris, Lloyd Peterson, and Stacy Kehrmeyer. 1989. The compost solution to dockside fish wastes. University of Wisconsin Sea Grant Institute, WISSG-89-434. http://aqua.wisc.edu/Publications/PDFs/CompostSolution.pdf

Paul, John, and Dieter Geesing. 2009. Compost facility operator manual: A compost facility operator training course reference and guide. Transform Compost Systems, Abbotsford, B.C., Canada.

Vandre, Wayne, and Marion Stirrup. 2008. Composting in coastal Alaska. University of Alaska Fairbanks Cooperative Extension Service, HGA-01021. http://www.uaf.edu/ files/ces/publications-db/catalog/anr/HGA-01021.pdf

Alaska Sea Grant is a marine research, education, and extension service at the University of Alaska Fairbanks School of Fisheries and Ocean Sciences. Alaska Sea Grant is supported by the National Oceanic and Atmospheric Administration Office of Sea Grant, Department of Commerce, under grant no. NA06OAR4170097 (projects A/161-02 and A/151-01), and by the University of Alaska with funds appropriated by the state.

For information on undergraduate and graduate opportunities in marine biology, fisheries, oceanography, and other marine-related fields at the University of Alaska Fairbanks School of Fisheries and Ocean Sciences, visit http://www.sfos.uaf.edu/.
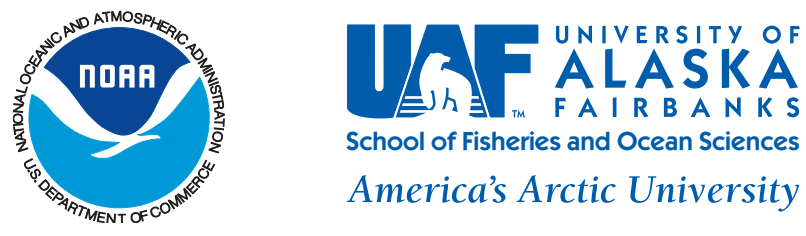
School of Fisheries and Ocean Sciences America's Arctic University
Marine Advisory Program University of Alaska Fairbanks 1007 West 3rd Ave., Suite 100

Anchorage, AK 99501

(907) 274-9691

map@sfos.uaf.edu

marineadvisory.org

\author{
Alaska Sea Grant \\ University of Alaska Fairbanks \\ PO Box 755040 \\ Fairbanks, AK 99775 \\ (888) 789-0090 \\ fypubs@uaf.edu \\ alaskaseagrant.org
}

